\title{
Functional outcome in primary nasolacrimal duct obstruction after successful external dacryocystorhinostomy surgery
}

\author{
Syed Ali Raza Rizvi ${ }^{1}$, Mohammad Saquib', Yogesh Gupta', \\ Rakesh Maheshwari' ${ }^{1}$ Puneet Maheshwari² \\ 'Institute of Ophthalmology,Jawaharlal Nehru Medical College, AMU, Aligarh UP, \\ India; ${ }^{2}$ Department of Oto-Rhino-Laryngology, Era's Lucknow Medical College and \\ Hospital, Lucknow, UP, India
}

\begin{abstract}
Aim: To assess the functional outcomes of external dacryocystorhinostomy (DCR) surgery in symptomatic patient with primary nasolacrimal duct obstruction.

Design: Prospective, clinical interventional study.

Methods: This study was conducted in initially 57 consecutive (57 eyes) patients and ultimately 50 consecutive (50 eyes) patients with primary acquired nasolacrimal duct obstruction admitted in a tertiary eye care center. Functional outcome comprises of symptom improvement which includes absence of epiphora, improvement in vision, routine work, occupational work, mood, embarrassment. Assessment was done by preand postoperative questionnaires at two, six and 12 months postoperatively.. Anatomic success was assessed by lacrimal syringing, fluorescein dye disappearance test (FDDT) and endoscopic view of osteotomy. Statistical significance between preoperative and postoperative symptoms (functional outcome assessment) was analyzed using the McNemar's test. Results: Postoperatively, marked improvement in subjective symptoms, i.e., difficulty in vision (93.5\%), routine work (95.6\%),occupational work (95.8\%), mood (95\%) and embarrassment (94\%) was seen with an anatomic success of $96 \%$.

Conclusions: In primary acquired nasolacrimal duct obstruction (PANDO) patients, symptoms bother the patient significantly. However, successful DCR surgery has a beneficial effect on the patient's physical and social health, thereby changing the quality of life of patients markedly.
\end{abstract}

Keywords: External dacrocystorhinostomy, PANDO, functional outcomes, anatomic success

\section{Introduction}

Primary acquired nasolacrimal duct obstruction (PANDO) is a common cause of epiphora in adults. ${ }^{1,2}$ Epiphora is a common, annoying symptom, embarrassing the patient both socially and functionally and it may even endanger the eye. It is interesting to note that nasolacrimal duct obstruction is a disorder in which the subjective problem does not always correlate with the objective findings. Patients also frequently complain of visual blur, difficulty in occupational work, routine work,

Correspondence: Syed Ali Raza Rizvi, Ophthalmic Plastic Surgery and Ocular Oncology Service, Institute of Ophthalmology,Jawaharlal Nehru Medical College, AMU, Aligarh.

UP.202002. India.

E-mail: dralirazal2@hotmail.com 
embarrassment, and poor mood due to nasolacrimal duct obstruction.

Anatomical success of DCR surgery based on patient's symptoms and severity of tearing may not always correlate. ${ }^{3}$ Evaluation of watering following surgery and professional and social impact are necessary to address objective successful surgery.

Until now, DCR has had objective anatomical measures of success. Previously published studies about DCR have shown that patient satisfaction may not necessarily correlate with objective success rates ${ }^{4,5} \mathrm{It}$ is felt that an evaluation of a broader range of symptoms related to watery eye was necessary to address the issue of whether patients had actually improved in real life terms following objectively successful surgery. Thus, the main aim of this study is to evaluate the functional outcomes (symptom improvement) in patients with nasolacrimal duct obstruction, evaluated prospectively before and after successful DCR surgery.

\section{Methods}

This prospective, clinical interventional study was conducted on 57 consecutive (57 eyes) in-patients of PANDO admitted in a tertiary eye care center. Informed consent was taken from all the patients who were included in the study. The purpose, method and basis of the study were conveyed to all of the patients recruited. The study was approved by the Institutional Ethics and Research Advisory Committee of the Institute and is according to the declaration of Helsinki.

All consecutive cases of PANDO admitted for surgery were included in the study. Exclusion criteria were children less than 12 years of age, canalicular or common canalicular block, failed DCR surgery, secondary nasolacrimal duct obstruction and patients unwilling to participate in the study.

All patients were subjected to detailed clinical evaluation which includes visual acuity measurement, Schirmer's test, lacrimal syringing, fluorescein dye disappearance test (FDDT) and nasal examination to rule out any contra-indication for DCR surgery.

A questionnaire was given to all the preoperative patients included in the study. Patients were asked about difficulty in vision, routine work, professional work, mood and embarrassment. The overall severity of this symptomology was graded as no symptoms at all (grade 0), mild (grade 1), moderate (grade 2) or severe symptoms (grade 3 ) (Table 1). ${ }^{6}$ 
Table $1 .{ }^{6}$ Questionnaire for Subjective Assessment.

\begin{tabular}{|l|l|c|c|}
\hline Does your watery-eye problem bother you? & & Y & $\mathrm{N}$ \\
\hline If it does bother you, does it interfere with your: & Vision? & Y & $\mathrm{N}$ \\
\hline & Routine work? & Y & $\mathrm{N}$ \\
\hline & Occupational work? & Y & $\mathrm{N}$ \\
\hline If it does interfere, is it: (choose one) & Mood? & Y & $\mathrm{N}$ \\
\hline & A little? (mild) & & \\
\hline & A moderate amount? & & \\
\hline Does your watery eye become embarrassing? & A great deal? (severe) & & \\
\hline If it does become embarrassing, is it: (choose one) & A little? (mild) & & \\
\hline & A moderate amount? & & \\
\hline & A great deal? (severe) & & \\
\hline
\end{tabular}

(Y-YES, N-NO)

Grading system: No symptoms - Grade 0; Mild symptoms - Grade 1; Moderate symptoms - Grade 2; Severe symptoms - Grade 3.

After informed consent, the patients underwent DCR surgery by external approach. All surgeries were performed under infratrochlear block with I.V sedation, by a single surgeon. External DCR were performed by a short ten-mm straight incision, positioned at half the distance between the medial canthus and mid-point of the nasal bridge and not extending above the level of the medial canthus.

A skin flap was raised, then orbicularis fibers were divided to reach the medial canthal tendon. The periosteum anterior to the medial canthal tendon was incised and reflected to expose the lacrimal fossa. The lacrimal sac was encountered and carefully reflected laterally exposing the fossa. A large osteotomy of $15 \times 15$ sq. mm was created. Nasal mucosal and lacrimal mucosal flaps were fashioned, the posterior flaps were sacrificed, and the anterior flaps were sutured using 6-0 Vicryl sutures. The medial canthal tendon was repositioned. To give subcutaneous sutures, 6-0 Vicryl was used as well and the skin was closed with fine 6-0 Prolene subcuticular sutures. Anatomic success include a patent lacrimal drainage system as determined by lacrimal syringing, fluorescein dye disappearance test, and endoscopic view of the osteotomy site.

Functional outcomes of surgery include absence of epiphora, decrease difficulty in vision, improved performance of routine and occupational work, better mood, and reduced embarrassment, which were assessed by post-operative questionnaires, conducted at two, six and 12 months following surgery. Seven patients were lost to follow-up, so ultimately the study was conducted on 50 (50 eyes) patients.

Statistical significance between preoperative and postoperative symptoms 
(functional outcome assessment) was analyzed using McNemar's test. Data were analyzed using SPSS version 20 . P-value $\leq 0.05$ was considered statistically significant.

\section{Results}

Out of 57 cases who underwent DCR, seven patients did not turn up for follow-up and were excluded from our study. In our study, the majority of the patients [16 (32\%)] were in age group of $41-50$ years. Of the total number of patients, there were 39 females (78\%) and 11 males (22\%). Nineteen (38\%) cases concerned the right side, 31 (62\%) cases the left side.

Out of 50 cases of PANDO, 31 (62\%) cases had difficulty in vision. Difficulty in routine work, occupational work and embarrassment in social gathering was seen in $23(46 \%), 24$ (48\%) and 19 (38\%) cases respectively. Mood disorder was the major problem in most of the cases of PANDO, namely 44 (88\%) (Table 2).

Although anatomic and functional success was assessed at different time intervals, the final outcome of success was measured at 12 months postoperatively to get unbiased results. Delayed assessment helped us to rule out early objective success and to include cases of late failure if there were any. Anatomic success in our study was seen in 48 (96\%) of cases 12 months postoperatively. After successful DCR surgery marked improvement was seen in subjective symptoms, i.e., difficulty in vision (93.5\%), routine work (95.6\%), occupational work (95.8\%), embarrassment (94\%) and mood (95\%) (Table 2). It was seen that symptoms of patient decreased significantly $(P<0.05)$ indicating that successful external dacrocystorhinostomy changed quality of life markedly in these patients (Fig. 1). Similarly, functional grading also improved significantly 12 months postoperatively $(P<0.05)$ (Table 3 ).

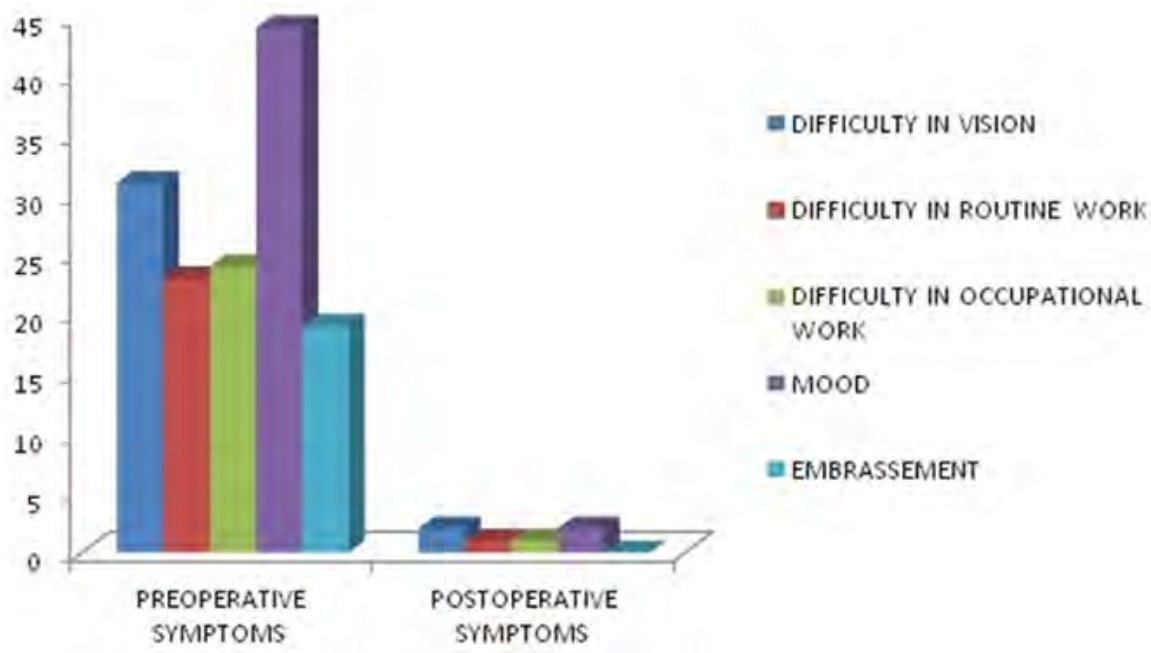

Fig. 1. Showing subjective symptoms preoperatively and 12 months postoperatively. 
Table 2. Effect of DCR surgery on symptoms of PANDO (functional outcome assessment).

\begin{tabular}{|l|l|l|l|l|l|}
\hline & $\begin{array}{l}\text { Difficulty } \\
\text { in vision }\end{array}$ & $\begin{array}{l}\text { Difficulty } \\
\text { in routine } \\
\text { work }\end{array}$ & $\begin{array}{l}\text { Difficulty in } \\
\text { occupational } \\
\text { work }\end{array}$ & Mood & Embarrassment \\
\hline Preoperative & $31(62 \%)$ & $23(46 \%)$ & $24(48 \%)$ & $44(88 \%)$ & $19(38 \%)$ \\
\hline $\begin{array}{l}\text { Postoperative } \\
\text { (12 months) }\end{array}$ & $\begin{array}{l}2 \\
(6.5 \%)\end{array}$ & $\begin{array}{l}1 \\
(4.4 \%)\end{array}$ & $\begin{array}{l}1 \\
(4.2 \%)\end{array}$ & $\begin{array}{l}2 \\
(5 \%)\end{array}$ & $\begin{array}{l}1 \\
(6 \%)\end{array}$ \\
\hline $\begin{array}{l}\text { Postoperative } \\
\text { improvement in } \\
\text { symptoms }\end{array}$ & $\begin{array}{l}29 \\
(93.5 \%)\end{array}$ & $\begin{array}{l}22 \\
(95.6 \%)\end{array}$ & $\begin{array}{l}23 \\
(95.8 \%)\end{array}$ & $\begin{array}{l}42 \\
(95 \%)\end{array}$ & $\begin{array}{l}18 \\
(94 \%)\end{array}$ \\
\hline P value & $<0.006$ & $<0.01$ & $<0.01$ & $<0.0001$ & $<0.05$ \\
\hline
\end{tabular}

Table 3. Grading of preoperative and postoperative symptoms at 12 months.

\begin{tabular}{|l|l|l|l|l|l|}
\hline $\begin{array}{l}\text { Preoperative } \\
\text { symptoms }\end{array}$ & Vision & $\begin{array}{l}\text { Routine } \\
\text { work }\end{array}$ & $\begin{array}{l}\text { Occupational } \\
\text { work }\end{array}$ & Mood & Embarrassment \\
\hline Grade 0 & $19(38 \%)$ & $27(54 \%)$ & $26(52 \%)$ & $6(12 \%)$ & $31(62 \%)$ \\
\hline Grade1 & $22(44 \%)$ & $14(28 \%)$ & $13(26 \%)$ & $27(54 \%)$ & $9(18 \%)$ \\
\hline Grade 2 & $6(12 \%)$ & $5(10 \%)$ & $8(16 \%)$ & $12(24 \%)$ & $8(16 \%)$ \\
\hline Grade 3 & $3(6 \%)$ & $4(8 \%)$ & $3(6 \%)$ & $5(10 \%)$ & $2(4 \%)$ \\
\hline $\begin{array}{l}\text { Postoperative } \\
\text { symptoms }\end{array}$ & Vision & $\begin{array}{l}\text { Routine } \\
\text { work }\end{array}$ & $\begin{array}{l}\text { Occupational } \\
\text { work }\end{array}$ & Mood & Embarrassment \\
\hline Grade 0 & $48(96 \%)$ & $49(98 \%)$ & $49(98 \%)$ & $48(96 \%)$ & $49(98 \%)$ \\
\hline Grade 1 & $1(2 \%)$ & $1(2 \%)$ & $1(2 \%)$ & $1(2 \%)$ & $1(2 \%)$ \\
\hline Grade 2 & $1(2 \%)$ & ------ & ------ & $1(2 \%)$ & -------- \\
\hline Grade 3 & ----- & ----- & ------ & ------ & ------- \\
\hline P value & $<0.05$ & $<0.05$ & $<0.05$ & $<0.05$ & $<0.05$ \\
\hline
\end{tabular}

\section{Discussion}

External DCR is the gold standard treatment for nasolacrimal duct obstruction because of patient acceptance, low cost, and high success rate. It can be performed safely under local anesthesia, on an outpatient basis, in elderly individuals. ${ }^{7-12}$

The outcome of external DCR surgery can be measured by both anatomical and functional indicators. It is being increasingly recognized that anatomical patency does not always translate into good functional outcome. Some patients with an anatomically patent nasolacrimal system still have subjective symptoms. ${ }^{13}$ Hence, 
both objective and subjective outcome should be assessed for the success of DCR surgery.

Olver ${ }^{14}$ in 2003 suggested that success rates should be measured and compared using strict outcome criteria taking in account both functional and anatomical success and an adequate length of follow-up. We have used the similar criteria to gauge the objective and subjective success after an eventful DCR surgery.

Rose ${ }^{15}$ describes the lacrimal paradox , where anatomical success may not correlate with success in control of symptoms and vice versa. He describes the signs and symptoms of drainage disorders to be either volume related or flow related. Volume-related backwash from the lacrimal sac can in most cases be treated with appropriate surgery. However, flow-related characteristics are largely due to limitation or tear conductance from the lateral canthus to the nose. Symptom relief of flow-related symptoms is not achievable in every patient.

Mansour et al. ${ }^{16}$ found that in 139 patients with PANDO who had external DCR, the subjective rate based on a retrospective symptom score was $89 \%$ after one year. They stated that anatomic patency does not always translate into good functional outcome, hence the functional outcome alone provide good pictures regarding DCR outcome. Lester ${ }^{17}$ took a sample size of 49 cases and nine months follow-up and concluded a functional success of 41 (83.7\%).

Mathew et al. ${ }^{18}$ described 'patient satisfaction' in a retrospective study and telephone questionnaire comparing non-laser endoscopic DCR and external $\mathrm{DCR}$, and found no significant difference between the two for patient satisfaction ( $75 \%$ vs $86 \%$, respectively). Tripathi et al. ${ }^{19}$ assessed the success of laser endonasal endoscopic DCR using both subjective (questionnaire) and objective (sac washout) measures..$^{15}$ The questionnaire asked to what degree the watering was cured, with $65 \%$ of patients declaring a complete cure, compared with $91 \%$ of patients with objective success.

Moore et al. ${ }^{20}$ evaluated mechanical and laser endoscopic DCR in 62 patients with PANDO including subjective reporting of tearing as an outcome measure. There was a $71 \%$ and $83 \%$ subjective success rate, respectively, but tearing alone was measured.

Cheung et al. ${ }^{6}$ evaluated a wide range of symptoms in patients with functional (FNLDO) and primary acquired nasolacrimal duct obstruction, before and after successful DCR surgery. Overall symptoms were significantly reduced following successful DCR surgery in FNLDO patients $(P<0.05)$ but remained unchanged in PANDO patients $(P=0.05)$. However, embarrassment was the only individual symptom to reduce significantly (in frequency) following surgery both in FNLDO ( $P$ $<0.005)$ and PANDO $(P<0.001)$. Also, there was a small but not statistically significant reduction in the frequency of the visual symptoms in both FNLDO and PANDO.

Similarly, our study has shown PANDO affects patients in relation to visual tasks, routine work, occupational work, mood and embarrassment.

In our study, $31(62 \%)$ cases had difficulty in vision. Raised tear meniscus of nasolacrimal duct obstruction particularly in down-gaze may be the cause of visual distortion. 
However, in our study marked improvement in all subjective symptoms, i.e., difficulty in vision, routine work, occupational work, mood and embarrassment, was seen and was found to be statistically significant $(P<0.05)$. Although $48(96 \%)$ patients had anatomical success in our study but symptomatic success in relation to routine work, occupational work and embarrassment was seen in 49 (98\%) cases (Table 3). This was attributed to the fact that out of the two patients who did not have a successful outcome after DCR surgery, one patient had much decreased epiphora with no complaints of discharge as compared to the preoperative status leading to decrease in these symptoms. So it was seen that the symptoms of the patients decreased significantly postoperatively, indicating that successful dacrocystorhinostomy changed quality of life markedly in our study.

Good anatomical success of DCR in our study depends on meticulous surgical steps, taut anterior flaps of lacrimal sac mucosa and nasal mucosa after suturing so that they do not sag down postoperatively and cover the osteotomy site, proper location of the osteotomy site, as well as large osteotomy which is the most important step in preventing failure of DCR, as larger osteotomies created during external DCR lead to larger postoperative ostia. ${ }^{21}$

We concluded that external DCR is a highly effective and safe procedure. In PANDO patients, symptoms may bother the patient significantly and successful DCR surgery has a positive effect on the patient's physical and psychological well-being.

\section{References}

1. Maini S, Raghava N, Youngs R, et al. Endoscopic endonasal laser versus endonasal surgical dacryocystorhinostomy for epiphora due to nasolacrimal duct obstruction: prospective, randomised, controlled trial. J Laryngol Otol 2007;121(12):1170-1176.

2. Walker RA, Al-Ghoul A, Conlon MR. Comparison of nonlaser nonendoscopic endonasal dacryocystorhinostomy with external dacryocystorhinostomy. Can J Ophthalmol 2011;46(2):191-195.

3. Sahlin S, Rose GE. Lacrimal drainage capacity and symptomatic improvement after dacryocystorhinostomy in adults presenting with patent lacrimal drainage systems. Orbit 2001;20:173-179.

4. Ibrahim HA, Batterbury M, Banhegyi G, McGalliard J. Endonasal laser dacryocystorhinostomy and external dacryocystorhinostomy outcome profile in a general ophthalmic service unit: a comparative retrospective study. Ophthal Surg Lasers 2001;32: 220-227.

5. Rosen N, Ashkenazi I, Rosner M. Patient dissatisfaction after functionally successful conjunctivodacryocystorhinostomy with Jones tube. Am J Ophthal 1994;117:636-642.

6. Cheung LM, Francis IC, Stapleton F, Wilcsek G. Symptom assessment in patients with functional and primary acquired nasolacrimal duct obstruction before and after successful dacryocystorhinostomy surgery: a prospective study. Br J Ophthalmol 2007;91(12):1671-1674.

7. Maini S, Raghava N, Youngs R, et al. Endoscopic endonasal laser versus endonasal surgical dacryocystorhinostomy for epiphora due to nasolacrimal duct obstruction: prospective, randomised, controlled trial. J Laryngol Otol 2007;121(12):1170-1176.

8. Walker RA, Al-Ghoul A, Conlon MR. Comparison of nonlaser nonendoscopic endonasal dacryocystorhinostomy with external dacryocystorhinostomy. Can J Ophthalmol 2011;46(2):191-195.

9. Jha KN, Ramalingam WVBS. External Versus Endoscopic Dacryocystorhinostomy: A Retrospective Study. MJAFI 2009;65(1):23-25.

10. Romanes GJ. Dacryocystorhinostomy. Clinical report of fifty cases. Br J Ophthalmol 1955;39:237-240. 
11. McPherson SD, Egleston D. Dacryocystorhinostomy: a review of 106 patients. Am J Ophthalmol 1959;47:328-331.

12. Pico G. A modified technique of external dacryocystorhinostomy. Am J Ophthalmol 1971;72:679-689.

13. GroessI SA, Sires BS, Lemke BN. An anatomical basis for primary acquired nasolacrimal duct obstruction. Arch Ophthalmol 1997;115(1):71-74. Erratum in Arch Ophthalmol 1997;115(5):655.

14. Olver JM. Tips on how to avoid the DCR scar. Orbit 2005;24:63-66.

15. Rose GE. The lacrimal paradox: towards a greater understanding of success in lacrimal surgery. Ophthal Plast Reconstr Surg 2004;20:262-265.

16. Mansour K, Sere M, Oey AG, et al. Long-term patient satisfaction of external dacryocystorhinostomy. Ophthalmologica 2005;219:97-100.

17. Lester SE, Robson AK, Bearn M. Endoscopic 'cold steel' versus laser dacryocystorhinostomy: completing the audit cycle. J Laryngol Otol 2008;122:924-927.

18. Mathew MR, McGuiness R, Webb LA, et al. Patient satisfaction in our initial experience with endonasal endoscopic non-laser dacryocystorhinostomy. Orbit 2004;2377-2385.

19. Tripathi A, Lesse THJ, O’Donnel NP, et al. Local anaesthetic endonasal endoscopic laser dacryocystorhinostomy: analysis of patients' acceptability and various factors affecting the success of this procedure. Eye 2002;16:146-149.

20. Moore WMH, Bentley CR, Olver JM. Functional and anatomic results after two types of endoscopic endonasal dacryocystorhinostomy: Surgical and holmium laser. Ophthalmology 2002;109:1575-1582.

21. Simon GJB, Brown C, McNab AA. Larger Osteotomies Result in Larger Ostia in External Dacryocystorhinostomies. Arch Facia Plast Surg 2012;14(2):127-131. 